bao-hiem-y-te-toan-dan-gop-phan-hieu-qua-trongcong-tac-bao-ve-cham-soc-suc-khoe-nhan-dan.

2. Bộ Y tế. Quyết định số $5481 / Q Đ-B Y T$ ngày $30 / 12 / 2020$ về việc ban hành tài liêu chuyên môn "Hướng dẫn chẩn đoán và điều trị Đái tháo đường Típ 2". 2020.

3. Christian Bommer, Esther Heesemann, Vera Sagalova, Jennifer Manne-Goehler, Rifat Atun, Till Bärnighausen, et al. The global economic burden of diabetes in adults aged 20-79 years: a cost-of-illness study. The Lancet Diabetes \& Endocrinology. 2017;5(6):423-30.

4. David R. Whiting, Leonor Guariguata, Clara Weil, Jonathan Shaw. IDF Diabetes Atlas: Global estimates of the prevalence of diabetes for 2011 and 2030. Diabetes Research and Clinical Practice. 2011;94(3):311-21.

5. Huy Tuan Kiet Pham, Thi Tuyet Mai Kieu, Tuan Duc Duong, Khoa Dieu Van Nguyen, Nam Quang Tran, Tien Hung Tran, et al. Direct medical costs of diabetes and its complications in Vietnam: A national health insurance database study. Diabetes Research and Clinical Practice. 2020;162:108051.

6. K. M. Pantalone, A. D. Misra-Hebert, T. M. Hobbs, X. Ji, S. X. Kong, A. Milinovich, et al. Clinical Inertia in Type 2 Diabetes Management: Evidence From a Large, Real-World Data Set. Diabetes care. 2018;41(7):e113-e4.

7. Nguyễn Thị Tuyết Nhung. Nghiên cứu về chi phí đợt điều trị nội trú của người bênh ĐTĐ tại Khoa Nồi tiết, Bênh viên Đa khoa tỉnh Bình Đinh năm 2011. Hà Nối: Trường Đại học Y tế công công; 2012.

8. Nguyễn Thị Bích Thủy, Vũ Xuân Phú, Nguyễn Quỳnh Anh. Chi phí trực tiếp chi cho y tế và chi phí trực tiếp chi ngoài y tế của người bệnh đái tháo đường tai khoa Nôi tiết, Bênh viên Thanh Nhàn, Hà Nội, năm 2013. Y học thực hành. 2013;893(11):6-10.

9. Nguyễn Hữu Lành. Chi phí của bệnh nhân đái tháo đường điều trị tại khoa Nội tiết Bệnh viện Nhân Dân Gia Đinh 115: Đai học Y Dược Thành phố Hồ Chí Minh; 2010.

\title{
ĐẶC ĐIỂM SÓNG TIỀN TÂM THU THẤT TRÁI TRÊN SIÊU ÂM TIM Ở BỆNH NHÂN ĐÁI THÁO ĐƯỜNG TYP 2
}

\section{TÓM TẮT}

Muc tiêu: Tìm hiểu đăc điểm sóng tiền tâm thu (STTT) thất trái trên siêu âm tim ở bệnh nhân (BN) đái tháo đường (ĐTĐ) typ 2. Đối tượng và phương pháp: Nghiên cứu mô tả, cắt ngang trên 60 BN ĐTĐ typ 2 và 30 người nhóm chứng tai khoa Nôi tiết và Viện Tim mạch Bệnh viện Bạch Mai từ tháng 8/2020 đển tháng 8/2021. Các thông số nghiên cứu (NC) trên siêu âm tim: vận tốc và thời gian sóng TTT đo tại đường ra thất trái, kích thước và chức năng tâm trương (CNTTr) thất trái. Kết quả: Tỉ lệ xuất hiện STTT thất trái trên siêu doppler tim ở bệnh nhân ĐTĐ typ 2 là $90 \%$, thấp hơn so với nhóm chứng (93\%) ( $p>0,05)$. Vận tốc STTT thất trái ở nhóm bênh nhân ĐTĐ typ 2 là $64.7 \pm 15.5 \mathrm{~cm} / \mathrm{s}$, lớn hơn so với vận tốc STTT thất trái ở nhóm chứng khỏe mạnh (56.2 \pm 11.3 $\mathrm{cm} / \mathrm{s})(\mathrm{p}<0.05)$. Vận tốc STTT ở nhóm ĐTĐ có rối loạn CNTTr thất trái cao hơn nhóm ĐTĐ không có rối loạn CNTTr thất trái $(74,3 \pm 11,3$ so với $58,5 \pm 11,2$, $\mathrm{p}<0,001)$. Thời gian STTT thất trái ở nhóm ĐTĐ typ 2 là $97.5 \pm 15.4 \mathrm{~ms}$ dài hơn nhóm người khỏe manh $(92.9 \pm 17.00 \mathrm{~cm} / \mathrm{s})(p>0,05)$. Không có sự khác biệt về thời gian sóng TTT giữa nhóm ĐTĐ có rối loạn

\footnotetext{
${ }^{1}$ Trường Đại học Y Hà Nội,

${ }^{2}$ Viện Tim mạch Việt Nam - Bệnh viện Bạch Mai

Chịu trách nhiệm chính: Lê Thị Mai Sao

Email: lemaisaomlvp@gmail.com

Ngày nhận bài: 17.8.2021

Ngày phản biên khoa hoc: 12.10.2021

Ngày duyệt bài: 20.10.2021
}

\section{Lê Thị Mai Sao ${ }^{1}$, Nguyễn Thị Thu Hoài ${ }^{2}$, Phạm Thị Hồng Thi² ${ }^{2}$, ỗ Thúy Cẩn ${ }^{2}$}

CNTTr và nhóm ĐTĐ không có rối loan CNTTr

Từ khóa: sóng tiên tâm thu thất trái; đái tháo đường typ 2; chức năng tâm trương thất trái

\section{SUMMARY \\ CHARACTERISTICS OF LEFT VENTRICULAR'S PRESYSTOLIC WAVE ON ECHOCARDIOGRAPHY IN TYPE 2 DIABETES MELLTTUS PATIENTS}

Aims: Describe Characteristics of left ventricular's presystolic wave on echocardiography in type 2 diabetes mellitus patients. Patients and methods: we performed a descriptive cross - sectional study included 90 patients: 60 type 2 diabetes mellitus patients and 30 healthy subjects in endocrinology department - Bach Mai hospital and Vietnam National Heart institue. The researched values included: velocity and times of the presystolic wave mesured in LVOT, size and diastolic function of the left ventricular. Result: The prevalence of left ventricular (LV) presystolic wave on doppler echocardiography of patients with diabetes mellitus 2 (DM2) is found to be $90 \%$, which is lower than that of the control group $(93 \%)(p>0,05)$. The wave velocity in DM2 patients is $64.7 \pm 15.5 \mathrm{~cm} / \mathrm{s}$, which is higher than that in the control group $(56.2 \pm 11.3 \mathrm{~cm} / \mathrm{s})(\mathrm{p}<0.05)$, and the velocity in DM2 patients with LV diastolic dysfunction is higher than in those with normal LV diastolic function. (74,3 $\pm 11,3$ and 58,5 $\pm 11,2$ respectively, $\mathrm{p}<0,001)$. The wave duration in DM2 patients is 97.5 $\pm 15.4 \mathrm{~ms}$, which is longer than that in the control group $(92.9 \pm 17.00 \mathrm{~cm} / \mathrm{s})(p>0,05)$. No noticeable difference in wave duration was observed between 
DM2 patients with LV diastolic dysfunction and those with normal LV diastolic function.

Keywords; left ventricular presystolic wave; diabetes mellitus type 2; left ventricular diastolic function

\section{I. ĐẶT VẤN ĐỀ}

Đái tháo đường là bệnh nội tiết và rối loạn chuyển hóa phổ biến nhất ở nhiều nước, gây ra nhiều biến chứng về tim mạch ${ }^{1}$. Suy tim ở bệnh nhân ĐTĐ trong đó suy CNTTr thường xuất hiện trước, thậm chí ngay cả giai đoạn bệnh chưa có triệu chứng lâm sàng trong khi chức năng tâm thu vẫn còn bình thường ${ }^{2}$. Do đó, việc chẩn đoán sớm các rối loạn ẩn dấu này, sẽ giúp các nhà lâm sàng có phương án chiến lược điều trị tốt nhất cho mỗi bệnh nhân. Sóng tiền tâm thu là một sóng thường được tìm thấy khi đánh giá tại đường ra thất trái bằng siêu âm doppler. Sự xuất hiện của STIT có liên quan đến sự kém chun giã̉n và độ cứng của tâm thất trái ${ }^{3}$. Đây là một chỉ dấu tương đối dễ thu thập trong quá trình thực hành siêu âm, góp phần vào đánh giá các rối loạn chức năng tim ở trên các bệnh nhân tim mạch, đặc biệt với các bệnh lý tim mạch liên quan đến ĐTĐ. Tuy vậy, dấu hiệu này hiện tại còn chưa được ứng dụng vào trong thực hành siêu âm tại Việt Nam, do đó, chúng tôi tiến hành $\mathrm{NC}$ này nhằm tìm hiểu đặc điểm của STTT thất trái trên siêu âm tim ở bệnh nhân ĐTĐ 2, từ đó làm cơ sở để góp phần đánh giá sớm rối loạn chức năng tim.

\section{II. ĐỐI TƯƠNGG VÀ PHƯƠNG PHÁP NGHIÊN CỨU}

Đối tượng nghiên cứu: $\mathrm{NC}$ được tiến hành trên $60 \mathrm{BN}$ ĐTÐ typ 2 (nhóm bệnh) và 30 người khỏe mạnh (nhóm chứng) điêu trị tại khoa Nội tiết và Viện tim mạch Bệnh viện Bạch Mai từ tháng $8 / 2020$ đến tháng $8 / 2021$.

- Nhóm bệnh: Chẩn đoán ĐTĐ typ 2 theo các tiêu chuẩn của Hiệp hội đái tháo đường Hoa Kỳ (ADA) năm 20194. BN đồng ý tham gia nghiên cứu.

Loại khỏi nhóm NC những trường hợp có các bệnh lý như bệnh cơ tim phì đại, bệnh mạch vành mạn tính, nhồi máu cơ tim, bệnh mạch máu ngoại biên, bệnh lý van tim từ vừa tới nặng, bệnh tim bẩm sinh, rung nhĩ, suy tim EF giảm, phụ nữ có thai, bệnh lý cấp cứu về bệnh nộingoại khoa.

- Nhóm chứng: Không có bệnh lý nội - ngoại khoa và đồng ý tham gia nghiên cứu

Phương pháp nghiên cứu: Nghiên cứu mô tả, cắt ngang. Tất cả BN nghiên cứu được hỏi tiền sứ, khám lâm sàng và chỉ định làm xét nghiệm cần thiết để xác định ĐTÐ typ 2. BN được làm siêu âm tim trên cùng hệ thống máy siêu ầm tim Vivid E95 (GE) với đầu dò ma trận 2D M5Sc-D, cho phép tính toán các thông số đánh giá chức năng tim và các thông số Doppler một cách tự động. Tất cả các đối tượng nghiên cứu (nhóm bềnh, nhóm chứng) đều được thực hiện siêu âm bởi cùng một bác sĩ chuyên về siều âm tim. Các thông số đánh giá: Vận tốc và thời gian STTT thất trái, đường kính và thể tích thất trái cuối tâm thu, đường kính và thể tích thất trái cuối tâm trương, chỉ số thể tích nhĩ trái (LAVI), vận tốc sóng $E$, sóng $A$, tỷ lệ $E / A$, vận tốc sóng e' vách, $e^{\prime}$ thành bên, vận tốc dòng hở ba lá. Các số liệu được thu thập theo mẫu bệnh án nghiên cứu và xử lý số liệu bằng phần mềm SPSS 16.0.

\section{KẾT QUẢ NGHIÊN CứU}

Đặc điểm chung của nhóm nghiên cứu. Trong thời gian từ tháng $8 / 2020$ đến tháng $8 / 2021$ chúng tôi đã NC trên 60 BN ĐTÐ typ 2 so với 30 đối tượng ở nhóm chứng, thấy không có sự khác biệt đáng kể về tỷ lệ nam/ nữ (41/19 so với $18 / 12, p=0.43)$ và tuổi trung bình $(54,1 \pm$ 11,2 so với $50,8 \pm 10,4, p=0.189$ ). Trong nhóm BN ĐTÐ có thời gian mắc bệnh trung bình là 6,1 $\pm 7,1$ năm, số lượng BN ĐTंĐ typ 2 mới mắc là 23 BN (25,6\%).

Đặc điểm sóng tiên tâm thu thất trái trên siêu âm tim ở bệnh nhân ĐTÐ typ2. đo bằng Simpson $>50 \%$ và 30 người nhóm chứng khỏe mạnh chúng tôi thấy rằng mặc dù phân suất tống máu thất trái trong giới hạn bình thường nhưng phân suất tống máu thất trái của nhóm ĐTĐ đã thấp hơn nhóm chứng $(62.7 \pm 3.5$ so với $65.2 \pm 3.8, p<0,05)$. Tuy nhiên không có sự khác nhau về hình thái của thất trái giữa nhóm ĐTÐ và nhóm chứng. Về rối loạn CNTTr thì đã có sự khác biệt giữa hai nhóm (bảng 1)

Bảng 1. Rôii loạn chức năng tâm trương ở nhóm nghiên cứu

\begin{tabular}{|c|c|c|c|c|c|c|c|}
\hline & \multicolumn{2}{|c|}{ Nhóm chung $(n=90)$} & \multicolumn{2}{|c|}{ Nhóm ĐTÐ $(n=60)$} & \multicolumn{2}{|c|}{ Nhóm chứng $(n=30)$} & \multirow{3}{*}{$\begin{array}{c}p \\
0,004\end{array}$} \\
\hline & Số lượng & Tỉ lệ \% & Số lượng & Tỉ lệ \% & Số lượng & Tỉ lệ \% & \\
\hline Rối loạn CNTTr & 23 & $25,6 \%$ & 21 & $35,0 \%$ & 2 & $6,7 \%$ & \\
\hline \multicolumn{8}{|c|}{ Phân độ rối loạn chức năng tâm trương } \\
\hline Đố 1 & 19 & 82,6 & 17 & 81,0 & 2 & 100 & \multirow{4}{*}{0,497} \\
\hline Đố 2 & 4 & 17,4 & 4 & 19,0 & 0 & 0 & \\
\hline Đố 3 & 0 & 0 & 0 & 0 & 0 & 0 & \\
\hline Độ 4 & 0 & 0 & 0 & 0 & 0 & 0 & \\
\hline
\end{tabular}


Tỷ lệ rối loạn CNTTr thất trái là 35\% (21BN) ở nhóm ĐTĐ trong đó $81 \%$ (17BN) là rối loạn CNTTr độ I, $19 \%$ (4BंN) là rối loạn CNTTr độ II. Có 6,7\% (2BN) trong nhóm chứng có rối loạn CNTTr thất trái (độ I).

Về các thông số của sóng tiền tâm thu thất trái, chúng tôi thu được kết quả như sau:

Bảng 2. Đặc điểm về sóng tiền tâm thu trên siêu âm tím

\begin{tabular}{|c|c|c|c|c|}
\hline \multicolumn{2}{|l|}{ Đặc điểm } & Nhóm ĐTÐ & Nhóm chứng & $\mathbf{P}$ \\
\hline \multirow{2}{*}{ Sóng tiền tâm thu $(n, \%)$} & Có & $54(90 \%)$ & $28(93,3 \%)$ & \multirow{2}{*}{0,600} \\
\hline & Không & $6(10 \%)$ & $2(6,7 \%)$ & \\
\hline \multicolumn{2}{|c|}{ Vận tốc sóng tiên tâm thu $(\mathrm{cm} / \mathrm{s})$} & $64.7 \pm 13.5$ & $56.2 \pm 11.3$ & 0.006 \\
\hline \multicolumn{2}{|c|}{ Thời gian sóng tiền tâm thu (ms) } & $97.5 \pm 15.4$ & $92.9 \pm 17.0$ & 0.132 \\
\hline
\end{tabular}

Tỉ lệ STTT ở nhóm ĐTĐ là $90 \%$, thấp hơn so với nhóm chứng $(93,3 \%)$. Sự khác biệt này chưa có ý nghĩa thống kê $(p>0,05)$. Vận tốc và thời gian STTT trung bình ở nhóm ĐTĐ lần lượt là $64.7 \pm 13.5$ và $97.5 \pm 15.4(\mathrm{~cm} / \mathrm{s})$. Vận tốc STTT ở nhóm ĐTÐ $(64.7 \pm 13.5)$ lớn hơn nhóm chứng $(56.2 \pm 11.3)$ $(p<0,05)$. Thời gian STTT ở nhóm ĐTĐ lớn hơn so với nhóm chứng, nhưng sự khác biệt chưa có ý nghĩa thống kê $(p>0,05)$.

Bảng 3. Sự khác biệt STTT ở bệnh nhân mắc đái tháo đường có rôi loạn chức năng tâm trương và không có rối loạn chức năng tâm trương

\begin{tabular}{|c|c|c|c|c|c|c|c|}
\hline & \multicolumn{3}{|c|}{ Rối loạn CNTTr } & \multicolumn{3}{c|}{ Không rối loạn CNTTr } & \\
\hline & $\mathrm{n}$ & $\mathrm{TB}$ & $\pm \mathrm{SD}$ & $\mathrm{n}$ & $\mathrm{TB}$ & $\pm \mathrm{SD}$ & $\mathrm{p}$ \\
\hline Thời gian sóng tiền tâm thu & 21 & 93.8 & 14.1 & 33 & 99.9 & 15.9 & 0.152 \\
\hline Vận tốc sóng tiền tâm thu & 21 & 74.3 & 11.3 & 33 & 58.5 & 11.2 & $\mathbf{0 . 0 0 0}$ \\
\hline
\end{tabular}

Vân tốc sóng TTT ở nhóm có rối loan CNTTr cao hơn nhóm không có rối loan CNTTr (74,3 $\pm 11,3$ so với $58,5 \pm 11,2, p<0,001)$. Không có sự khác biệt về thời gian sóng TTT giửa 2 nhóm nghiên cứu, $\mathrm{p}>0,05$.

\section{BÀN LUẬN}

Theo kết quả NC của chúng tôi, STTT thất trái xuất hiện ở 91,1\% nhóm chung, $90 \%$ nhóm ĐTÐ và $93,3 \%$ ở nhóm chứng $(p: 0,600)$. Theo NC của Kul ${ }^{3}$ và cs (2019) trên 120 BN ĐTĐ typ 2, thì tỉ lệ sóng TTT thất trái ở BN ĐTĐ là $69 \%$. Nghiên cứu của Ozmen ${ }^{5}$ ghi nhận tỷ lệ xuất hiện STTT thất trái thấp hơn các nghiên cứu khác, chiếm $46 \%$ bệnh nhân thận nhân tạo và $18,1 \%$ ở bệnh nhân nhóm chứng. Cũng trong NC của chúng tôi, vận tốc STTT trung bình là $61.8 \pm$ $13.4 \mathrm{~cm} / \mathrm{s}$, trong đó vận tốc STT ở nhóm bênh ĐTÐ $(64.7 \pm 13,5 \mathrm{~cm} / \mathrm{s})$ lớn hơn nhóm chứng $(56.2 \pm 11.3 \mathrm{~cm} / \mathrm{s})$ có ý nghĩa thống kê $(p<0.05)$. Nghiên cứu của Mittal ${ }^{6}$ và cộng sự trên bệnh nhân THA có tổn thương chức năng thất trái cũng nhận thấy vận tốc STTT ở nhóm bệnh cao hơn so với nhóm chứng (45.23 \pm 11.97 so với $28.16 \pm 8.54, p<0.001$ ). Nghiên cứu của Joshi ${ }^{7}$ và cộng sự đánh giá về ứng dụng lâm sàng của STTT, vận tốc STTT ở nhóm PSTM < 55\% thấp hơn so với nhóm EF bình thường ( $37 \pm 10$ vs 48 $\pm 16 \mathrm{~cm} / \mathrm{s}, \mathrm{p}<0.0001$ ).

Trên bệnh nhân đái tháo đường, sẽ có nhiều các biễn đổi bệnh lý ảnh hưởng đến cấu trúc cơ tim, dẫn đến những thay đổi về mặt mô học như dày thất trái, tăng sinh tế bào xơ dẫn tới tắng độ cứng của tố chức ngoài tế bào cơ tim, giảm độ đàn hồi tâm thất. STTT thất trái có nguồn gốc từ các dòng chảy xoáy do dòng máu khi đổ từ van
2 lá vào thất trái tạo ra, do đó những tính chất của buồng thất trái sẽ ảnh hưởng đến vector dòng chảy này. Sự gia tăng độ cứng của thất trái sẽ làm gia tăng áp lực thất trái vào thời kỳ nhĩ trái thu, và chính yếu tố này làm tăng động năng của dòng xoáy, do đó sẽ dẫn đến sự tăng vận tốc của sóng TTT. Đến những giai đoạn sau, khi thất trái trở nên giãn ra, lúc này, do sự phân tán của momen động năng của dòng chảy qua van 2 lá, sẽ khiến cho momen lực trở nên rất yếu và các sóng này sẽ trở nên giảm vận tốc đồng thời tỷ lệ xuất hiện STTT đo ở ĐRTT sẽ giảm dần. Trong NC của chúng tôi, các đối tượng nc đều ở giai đoạn chưa thay đổi về hình thái thất trái mà chỉ ở giai đoạn rối loạn chức năng tâm trương (thay đổi về độ cứng, độ đàn hồi của thất trái), điều này lý giải việc tỉ lệ xuất hiện STTT đo ở ĐRTT ở nhóm bệnh không có sự khác biệt so với nhóm chứng, nhưng đã có sự thay đổi về vận tốc STIT giữa các nhóm, cụ thể là vận tốc STTT ở nhóm ĐTÐ cao hơn nhóm chứng, và trong nhóm ĐTÐ thì nhóm có rối loạn chức năng tâm trương có vận tốc sóng TाT cao hơn nhóm không có rối loạn chức năng tâm trương.

Như vậy qua kết quả về các đặc điểm của STTT, có thể thây tổn thương sự co giãn của tâm thất trái và gia tăng độ cứng có ảnh hưởng đến sự xuất hiện sóng TTT ở bệnh nhân ĐTĐ và việc theo dõi và đánh giá vân tốc STTT thất trái có giá trị nhất định trong đánh giá rối loạn chức 
năng tâm trương trên nhóm bệnh nhân đái tháo đường.

\section{KẾT LUẬN}

- Tỷ lệ sóng TाT thất trái là $90 \%$ ở nhóm ĐTÐ, 93,3\% ở nhóm chứng nhưng sự khác biệt chưa có ý nghĩa thống kê $(p>0,05)$.

- Vận tốc STTT thất trái ở nhóm bệnh nhân ĐTÐ typ 2 là $64.7 \pm 15.5 \mathrm{~cm} / \mathrm{s}$, lớn hớn so với vận tốc STTT thất trái ở nhóm chứng khỏe mạnh $(56.2 \pm 11.3 \mathrm{~cm} / \mathrm{s})(\mathrm{p}<0.05)$.

- Vận tốc STTT ở nhóm ĐTĐ có rối loạn CNTTr cao hơn nhóm ĐTĐ không có rối loạn $\operatorname{CNTTr}(74,3 \pm 11,3$ so với $58,5 \pm 11,2, \mathrm{p}<0,001)$.

\section{TÀI LIÊU THAM KHẢO}

1. Trân Hữu Dàng, Thái Hồng Quang, \& Nguyễn Hải Thủy và CS. Bệnh lý tim mạch và các khuyến cáo điều trị các nguy cơ tim mạch ở bệnh nhân đái tháo đường. Hội Nội Tiết Và Đái Tháo Đường Việt Nam (2018).

2. Patil, V. C., Patil, H. V., Shah, K. B., Vasani, J. D. \& Shetty, P. Diastolic dysfunction in asymptomatic type 2 diabetes mellitus with normal systolic function. J. Cardiovasc. Dis. Res.2, 213222 (2011).

3. Kul, S. et al. Presystolic Wave is Associated with Subclinical Left Ventricular Dysfunction Assessed by Myocardial Performance Index in Type 2 Diabetes Mellitus. Arq. Bras. Cardiol. (2019) doi:10.5935/abc.20190134.

4. American Diabetes Association. Classification and Diagnosis of Diabetes ADA 2019. Diabetes Care42, S13-S28 (2019).

5. Özmen C, Kaya B, Eker Akıllı R, et al. The presystolic wave was not sufficient for diagnosing subclinical left ventricular diastolic dysfunction in hemodialysis patients. Cukurova Med J. 2019;44:529-538. doi:10.17826/cumj.623583

6. Mittal SR, Pancholi N. Left ventricular outflow tract presystolic flow velocity - another marker of left ventricular diastolic function. Published online 2001:8-13

7. Joshi KR, Kabirdas D, Romero-Corral A, Shah M, Figueredo VM, Pressman GS. Clinical Significance of a Presystolic Wave on Doppler Examination of the Left Ventricular Outflow Tract. Am J Cardiol. 2014;114(10):1599-1602. doi:10.1016/j.amjcard.2014.08.048.

\section{KẾT QUẢ HÓA XẠ TRI (IMRT) ĐỒNG THỜI UNG THƯ THANH QUẢN GIAI ĐOẠN III - IV TẠI BỆNH VIỆN K}

\section{TÓM TẮT}

Mục tiêu: Nhận xét một số đặc điểm lâm sàng, cận lâm sàng và đánh giá kểt quả hóa xạ trị đồng thời bệnh nhân ung thư thanh quản giai đoạn III-IV tại BV $\mathrm{K}$ giai đoạn 2018 - 2021. Đối tượng và phương pháp nghiên cứu: Nghiên cứu mô tả trên 31 bệnh nhân ung thư thanh quản giai đoạn III - IV tại bệnh viện K giai đoạn 2018 - 2021.Các bệnh nhân được hóa xạ trị đônng thời triệt căn. Mô tả một số đặc điểm lâm sàng, cận lâm sàng và đánh giá kểt quả điều trị.-Kết quá: Tuổi trung bình 58,6 $\pm 7,1$. Tỷ lệ nam/nữ là 30/1. Tỷ lệ nuốt vướng 41,9\%, khàn tiếng 41,9\%. Vị trí khối u ở thượng thanh môn chiếm $67,7 \%$. Có 18 $(58,1 \%)$ bệnh nhân giai đoạn III và $13(41,9 \%)$ bệnh nhân ở giai đoạn IVa. Có $77,4 \%$ bệnh nhân sử dụng phác đồ điều trị này là do từ chối phẫu thuật. Tỷ lệ đáp ứng toàn bộ sau hóa xa trị là $87 \%$, tỷ lệ đáp ứng 1 phân là $13 \%$, không có bênh nhân nào không đổi sau điều trị. Độc tính trên hệ huyết học là hạ bạch câuu độ II $(25,8 \%)$, hạ tiểu câu độ II $(19,4 \%)$. Độc tính

\footnotetext{
${ }^{1}$ Trường Đại học Y Hà Nội

${ }^{2}$ Bềnh viện $K$

Chịu trách nhiệm chính: Bùi Sơn Hải

Email: buisonhaibvk@gmail.com

Ngày nhận bài: 20.8.2021

Ngày phản biên khoa học: 13.10.2021

Ngày duyệt bài: 21.10 .2021
}

\section{Bùi Sơn Hải ${ }^{1}$, Ngô Thanh Tùng ${ }^{2}$}

viêm da độ II do xạ trị (38,7\%), viêm miệng độ III do xa trị $(45,2 \%)$. Kêt luận: Phác đồ cho tỷ lệ đáp ứng tổt, an toàn, độc tính chấp nhận được.

Tư khóa: Ung thư thanh quản, hóa xạ trị đồng thời, IMRT, giai đoạn III-IV

\section{SUMMARY}

\section{THE RESULTS OF CONCURRENT CHEMORADIOTHERAPY (IMRT) FOR LARYNX CANCER STAGE III - IV AT NATIONAL CANCER HOSPITAL}

Objective: Describe clinical characteristics and evaluate outcome of chemoradiotherapy in patients with stage III - IV larynx cancer at National Cancer Hospital. Material and Method: A descriptive crosssectional study performed on 31 patients with stage III - IV larynx cancer at National Cancer Hospital from 2018 to 2021. The patients received definitive concurrent chemoradiotherapy. Describe some clinical and para-clinical characteristics and evaluate treatment results. Results: The average age was 58.6 \pm 7.1 years [41-69]. The male/female ratio was 30/1. The rate of dysphagia was $41.9 \%$. The site of lesions at supraglottic accounted for $67.7 \%$. There were 18 $(58.1 \%)$ stage III patients and $13(41.9 \%)$ patients at stage IVa. There were $77.4 \%$ of the patients treated with this protocol because of refusal of surgery. The overall response rate after chemoradiation was $87 \%$, the partial response rate was $13 \%$. Toxicity grade II 